\title{
La brecha ética: por qué los alemanes desestiman a los periodistas y no confían en ellos
}

\author{
Wolfgang Donsbach, Mathias Rentsch, Anna-Maria Mende \\ Technische Universität, Dresden, Alemania
}

\section{Resumen}

Recibido: 21 de noviembre de 2012

Aceptado: 27 de noviembre de 2012

En la mayoría de las democracias, la reputación pública de los periodistas está en declive. Sin embargo, el mapa cognitivo que el público tiene del periodismo no ha recibido mucha atención salvo en lo concerniente a partidos y a políticos. Este artículo describe los resultados de una encuesta representativa por teléfono de la población alemana $(\mathrm{N}=1.054)$ diseñada para explorar la percepción pública del periodismo. El artículo contiene un primer análisis de estos datos. Nuestros resultados confirman que la reputación pública de los periodistas es negativa, particularmente en cuanto a su confiabilidad, y especialmente entre los más jóvenes. También se observa una gran brecha entra las expectativas del público y su percepción de los verdaderos objetivos y valores del periodismo, las características del contenido de las noticias y la conducta de los periodistas frente a dilemas éticos. En la última parte del artículo, se prueban los efectos de algunas de estas variantes en la confianza y la estima. El trabajo se basa en la suposición de que la relación entre las personas y la prensa merece ser más estudiada, porque una relación exitosa entre ambos es el fundamento de una democracia que funciona correctamente.

Palabras clave: periodistas, Alemania, ética, percepción pública, política.

\section{The ethics gap: why Germans have little esteem and no trust in journalists}

\section{Abstract}

In most democracies, the public reputation of journalists is on the decline. However, other than with attitudes towards parties and politicians, the concrete cognitive map that people have of journalists has received rather little attention. This paper describes the results of a representative telephone survey of the German population $(\mathrm{N}=1,054)$ that was designed to explore the public's perception of journalism. The paper contains a first analysis of these data. Our results confirm a rather negative public reputation of journalists, particularly concerning the profession's trustworthiness and here especially among the younger population. While two thirds of respondents have esteem for journalists, only a 
third trust journalists. We further found large gaps between the public's expectations and the public's perceptions of journalistic goals and values, characteristics of news content, as well as journalists' behavior in ethical dilemmas. In the final part of the paper we test the effects of some of these variables on trust and esteem. Our work is based on the assumption that the relationship between the people and the press deserves more research because a functioning relationship between both actors is the basis for a functioning democracy.

Keywords: journalists, Germany, ethics, public perception, politics.

\section{A brecha ética: porque os alemães subestimam os jornalistas e não confiam neles \\ Resumo}

Na maioria das democracias, a reputação pública dos jornalistas está em queda. Contudo, o mapa cognitivo que o público tem do jornalismo não há recebido muita atenção salvo que concerne a partidos e a políticos. Este artigo descreve os resultados de uma enquete representativa por telefone feita com o povo alemão para fazer um levantamento da percepção pública do jornalismo. Os artigos contêm a primeira análise desses dados. Nossos resultados confirmam que a reputação pública dos jornalistas é negativa, particularmente em relação à sua confiabilidade e especialmente entre os mais jovens. Também se observa uma grande brecha entre as expectativas do público e a percepção dos verdadeiros objetivos e valores do jornalismo, as características do conteúdo das notícias e a conduta dos jornalistas em relação a dilemas éticos. Na última parte do artigo, provam-se os efeitos de algumas destas variantes na confiança e na estima. O trabalho se baseia na suposição de que a relação entre as pessoas e a imprensa merece ser mais estudada, porque uma relação exitosa entre ambos é o fundamento de uma democracia que funciona corretamente.

Palavras chave: jornalistas, Alemanha, ética, percepção pública, política.

\section{Introducción: Cambios y desafíos del periodismo profesional}

Las actitudes hacia el periodismo y los periodistas - es decir, su reputación, su credibilidad, la confianza depositada en ellos y la percepción pública de su conformidad con estándares profesionales- empeoraron en los últimos años en casi todas las democracias occidentales. Según un sondeo reciente, solamente el 31 por ciento de la población alemana confía al menos un poco en el trabajo de los periodistas (GfK Custom Research, 2007).

La reputación profesional y la credibilidad de otras profesiones, como la abogacía, la consultoría impositiva y el liderazgo gremial, son antes que nada claves para sus respectivos negocios y sus relaciones con los clientes. En cambio, la imagen de los periodistas - como la de los políticos- es de gran importancia para el funcionamiento de una sociedad. Una estructura de comunicación libre o un 
sistema de medios masivos solo puede producirse si el individuo confía en los responsables de la comunicación y en su trabajo. Si esta confianza desaparece - $\mathrm{O}$ si nunca llegó a existir, como en las sociedades no democráticas-, los ciudadanos carecerán de una base objetiva para formar sus opiniones. Como resultado, podrían dejar de usar los contenidos de los medios profesionales y en consecuencia también dejar de formar opiniones sobre cuestiones de interés público. Incluso podrían terminar concentrándose en ciertos medios partidarios que se ajusten a sus tendencias políticas individuales y que ellos consideren creíbles.

El hecho de que la estima en el periodismo haya decrecido en los últimos años puede explicarse por diversos factores:

Primero, ocurrió una inflación mediática y en consecuencia, una inflación periodística. Cada vez se abren más medios de comunicación dentro de los medios tradicionales facilitados por desarrollos técnicos como la digitalización, de la misma manera que aparecen medios totalmente nuevos, en primer lugar internet, que condujeron hacia el suministro sin precedentes de canales, programas, formatos y actores comunicacionales. Las épocas en las que los periodistas suponían una especie distinta y escasa de actores públicos, conocidos por casi la totalidad de sus respectivas audiencias, han terminado.

Segundo, varios escándalos mediáticos afectaron la percepción pública del periodismo (Wiegerling, 1998). Podemos distinguir entre dos categorías: los escándalos que surgieron de lo relatado y aquellos que se conocieron de la forma en que los periodistas llevaron a cabo sus investigaciones. A la primera categoría pertenecen las noticias inventadas del cronista de The New York Times Jayson Blair y el corresponsal de Suddeutsche Zeitung Tom Kummer. Más famosos todavía fueron los casos de conductas poco éticas en la investigación o en la cobertura de las noticias, entre los cuales la cacería de Lady Diana se destaca como el más conocido y discutido.

Una tercera razón del aumento en las discusiones críticas sobre el periodismo podría ser el énfasis cada vez mayor de los factores económicos en las decisiones editoriales. En los últimos veinte años se volvió más obvio que nunca que la rentabilidad es el motor más fuerte detrás de las noticias. Las consecuencias de este acontecimiento pueden observarse en la expansión del formato tabloide, en el desplazamiento de las noticias duras por las noticias blandas, en la reforzada influencia de los anunciantes y en la fusión parcial del periodismo con las relaciones públicas. Gradualmente, los medios de noticias derribaron el muro entre la redacción y el departamento de publicidad. 
Una cuarta razón puede encontrarse en el contenido de los medios. La proporción creciente de noticias negativas - comprobada por numerosos estudios empíricos en todo el mundo- puede haber influido en la percepción de los medios. Parafraseando a McLuhan, se podría argumentar que el medio se convirtió en algo parecido a su mensaje: es decir, en algo negativo y sucio. Muchos estudios muestran también que las audiencias no están interesadas en tantas noticias negativas como les ofrecen los medios (Patterson, 2000). Nuestro estado de alerta automático contra señales negativas (Prato \& John, 1991) se contrarresta por nuestro deseo de control. Mientras mejor y más favorable sea nuestra realidad, mayor será nuestra percepción de control, lo que podría explicar el hallazgo de Haskins y Miller (1984), quienes expusieron que la proporción de noticias negativas afecta la evaluación pública del periódico.

Finalmente, las nuevas tecnologías de comunicación afectaron la identidad y el alcance del periodismo. Emergieron nuevas actividades y roles profesionales y sociales, los cuales, aunque a menudo parezcan y suenen como periodismo, no lo son, por lo menos en el sentido profesional del término. Los blogs, los wikis y las plataformas como YouTube exhiben contenidos similares a las noticias que, sin embargo, no son producidos bajo las condiciones del periodismo profesional. Hoy en día, la mayoría de las personas puede no solo "comunicarse", lo que siempre ha sido posible, sino también simular hacerlo como un periodista. Es un acontecimiento que debería ser celebrado en una sociedad libre, pero que también pone en cuestión hasta qué punto el público todavía distingue entre las noticias redactadas en un proceso profesional con controles y equilibrios y las pseudonoticias que representan antes que nada cosmovisiones subjetivas o mensajes de relaciones públicas guiados por intereses subjetivos.

En este estudio se intenta evaluar cómo el público alemán percibe a los periodistas y qué factores afectan la confianza y estima en la profesión.

\section{Estudio del periodismo y el público}

Aunque existen muchos estudios que se ocupan de los periodistas - es decir, sus actitudes, sus condiciones laborales, sus modelos periodísticos, etc. - solo unos pocos toman en cuenta el rol del público. De todos modos, se pueden distinguir cinco áreas de investigación que se ocupan del periodismo y el público: la coorientación de los periodistas y el público, las expectativas del público en torno de las tareas periodísticas, la exposición mediática, la evaluación pública del con- 
tenido mediático y la reputación de los periodistas (su credibilidad, la confianza y la estima que inspiran en los lectores).

\subsection{Coorientación de los periodistas y el público}

La relación entre las actitudes de los periodistas y las del público puede describirse con dos teorías en conflicto. La "teoría del espejo" sugiere que los medios funcionan como un espejo de la opinión pública. Esta suposición es uno de los fundamentos del principio de la libertad de prensa y, por lo tanto, puede considerarse como una justificación de los privilegios y del impacto de los medios en la sociedad. La "teoría del órgano", mientras tanto, argumenta que son los medios los que generan la opinión pública. Ambas teorías tienen sus raíces en los debates sobre la libertad de prensa en el siglo XIX. La pregunta de si el periodismo es un espejo o un generador de la opinión pública está ligada a la legitimación de la profesión (Donsbach, 1982). Si los medios fueran simplemente generadores de opiniones públicas extrañas a las opiniones y actitudes del público estaría debilitada la representación de distintas opiniones en una democracia.

Martin, O’Keefe y Nayman (1972) usaron el modelo de coorientación —desarrollado originalmente por McLeod y Chaffee (1972) para analizar las relaciones interpersonales- con el fin de estudiar la relación entre las opiniones de los periodistas y las del público. Les preguntaron a lectores y a editores de periódicos qué opinaban sobre determinados temas candentes y cómo percibían las opiniones del segundo grupo. Las opiniones de los lectores y de los editores discreparon en gran medida, por lo que la correlación entre ambos grupos resultó ser bastante pobre. Los periodistas fueron más perceptivos de las opiniones del otro grupo que los lectores. A su vez, los periodistas pensaron que sus opiniones eran más congruentes con las del público de lo que eran en realidad. Otros estudios también encontraron divergencias entre las opiniones de los periodistas y las del público (Kepplinger, 1979). Algunos de ellos advirtieron que las opiniones de los periodistas no solo toman distancia de la población sino también de otras élites sociales.

Las orientaciones políticas de los periodistas son unas de las preocupaciones centrales de estas investigaciones. Muchos estudios determinaron que generalmente los periodistas tienden más hacia la izquierda que el resto de la población (por ejemplo, en Alemania: Weischenberg et al., 2006; en Estados Unidos: Dautrich \& Necci Dineen, 1996). Casi la mitad de los periodistas alemanes se ubicarían a sí 
mismos a la izquierda de la orientación política de sus lectores (Lang et al., 1993; ver también Ehmig, 2000).

Estos hallazgos resultan especialmente interesantes, ya que los estudios sugieren que la selección de las noticias no es independiente de las actitudes de los periodistas (por ejemplo, D’Alessio \& Allen, 2000). Numerosas investigaciones determinaron que los periodistas tienden a seleccionar la información según su coherencia con la inclinación política del diario expresada en los editoriales (proceso llamado "sincronización", por ejemplo en Schönbach, 1977). Hagen (1992) encontró que las fuentes expertas son seleccionadas a partir de su afinidad con la inclinación política del medio. Según un estudio de Kepplinger (1989), los periodistas les asignan más valor a informaciones que respalden sus opiniones sobre temas candentes que a informaciones que contradigan sus posturas. Un sondeo comparativo demostró que la correlación entre las opiniones de los periodistas y sus determinaciones periodísticas es particularmente alta entre los periodistas alemanes (Patterson \& Donsbach, 1996).

Además, las percepciones de los periodistas acerca de las actitudes del público no siempre son correctas. Bernt et al. (2000) advirtió que los periodistas en Estados Unidos tienden a sobreestimar el interés de su audiencia en el crimen, la religión y los deportes. Otros estudios adelantaron que los periodistas tienden a sobreestimar el interés del público en el entretenimiento, mientras que subestiman la necesidad de información de sus lectores (Glotz \& Langenbucher, 1969; NoelleNeumann \& Kepplinger, 1978). De todos modos, nuevos estudios sugieren que las necesidades del público se volvieron más importantes en las últimas décadas al orientar el trabajo periodístico (Hohlfeld, 2005; Weischenberg, Malik \& Scholl, 2006).

Obviamente, no siempre es fácil que los periodistas tengan una idea clara de los lectores, o viceversa, porque se establecen pocas interacciones directas entre ambos (Engesser, 2003). Si bien el público lee o escucha el trabajo de los periodistas diariamente, los periodistas, aunque podrían usar sondeos de opinión pública o estudios de mercado realizados por sus propios medios para conocer mejor a su audiencia, apenas aprovechan estas posibilidades.

Para concluir, los periodistas no son para nada representativos de la población. Lo que puede ser una ventaja por el nivel de educación de los periodistas y hasta algunas de sus actitudes y valores. Pero la discrepancia entre las posturas políticas 
de ambos es una desventaja, porque puede interferir en el rol del periodista como proveedor neutral de información.

\subsection{Las expectativas del público acerca de las tareas periodísticas}

Mientras que la mayoría de los estudios se concentra en el análisis de lo que los mismos periodistas entienden por su rol y sus deberes (por ejemplo, en Köcher, 1986; Donsbach, 2008; Weaver, 1998; Weaver, Beam \& Brownlee, 2008), son escasos los datos sobre las expectativas del público. La pregunta, obviamente, sería si la audiencia entiende el rol de los medios en una democracia y si, en consecuencia, guarda expectativas puntuales sobre el deber de los periodistas.

Un estudio alemán inédito (Schriefers, 1992) comparó las expectativas del público sobre el rol del periodismo con los resultados de un sondeo anterior hecho a periodistas (Donsbach, 1982; Köcher, 1986). Schriefers (1992) encontró que el público prefiere que los periodistas tengan un rol más "pasivo" y "neutral" que lo que pretenden los mismos periodistas. Al ser consultados sobre la influencia que los periodistas deberían ejercer en la formación de opiniones, la muestra de ciudadanos eligió, en una escala del 1 al 10, un puntaje promedio de 4,5. Cuando fueron consultados sobre la influencia que los periodistas realmente ejercen en la formación de opiniones, la calificación promedió los 7 puntos en la misma escala (Schriefers, 1992). Al contrario, los periodistas calificaron tanto su influencia real como la que deberían ejercer con el mismo puntaje (5,9 contra 6,0: Donsbach, 1982: 101).

Desde 1985, el Pew Research Center for the People and the Press le consulta regularmente a la población estadounidense si las críticas periodísticas distraen a los políticos o si previenen que estos últimos cometan errores. Desde un cuarto hasta un tercio de los encuestados considera que una prensa demasiado crítica es contraproducente para la sociedad (Pew Research Center, 2007). Además, el apoyo del público hacia el periodismo de investigación se encuentra en declive (Weaver \& Daniels, 1992; Willnat \& Weaver, 1998). Asimismo, el 58 por ciento de los consultados del sondeo de Pew consideró que es importante que los medios critiquen a la política para que, de esta manera, contribuyan al control democrático de los políticos (Pew Research Center, 2007: p. 8). 


\subsection{Exposición mediática}

Se podrían interpretar los datos de exposición mediática como indicadores de las actitudes del público hacia el periodismo y los medios. Según este argumento, se podría suponer que las actitudes del público son bastante positivas, ya que el tiempo que la persona promedio dedica a los medios incrementó en las últimas décadas. En 2005, el alemán promedio dedicó alrededor de 10 horas (!) diarias a los medios, de las cuales 221 minutos fueron destinados a la radio y 220 minutos a la televisión (Ridder \& Engel, 2005: p. 422-449). Un 89 por ciento de la población alemana miró televisión diariamente, el 84 por ciento escuchó la radio todos los días, el 51 por ciento leyó los diarios y el 28 por ciento usó internet diariamente (loc. cit.). Más del 90 por ciento de los encuestados aseguraron usar la televisión, los diarios e internet principalmente para mantenerse informados (p. 428). Pero los medios también se usaron por una variedad de razones, como el entretenimiento o el escapismo, junto con otras actividades (como ver la televisión durante la comida, escuchar la radio durante un viaje en auto, etc.) o hasta en simultáneo con otros medios (como escuchar la radio durante una navegación por internet).

Las investigaciones sobre el uso de los medios y los datos sobre las conductas del público demuestran, sin embargo, que este admite la gran importancia de los medios como la fuente de información en el proceso de formación de opiniones (p. 438). El uso público de los medios también determina el rol que los medios o un medio en particular pueden jugar dentro de la sociedad. Pero los datos del uso de los medios, por su propia cuenta, no pueden explicar los motivos de la relación cambiante entre el público y el periodismo.

\subsection{Escepticismo mediático en alza: la evaluación del público del contenido mediático}

La evaluación de los medios a través del público cambió durante los últimos años y décadas. En Alemania, la calificación del nivel "informativo" de los medios es más baja ahora que en los 70 y los 80 ; solamente subió la calificación de internet, aunque sigue promediando por debajo de los demás medios (Ridder \& Engel, 2005: p. 432) ${ }^{1}$. Tsfati y Cappella (2003: p. 506) describieron este desarrollo en Estados Unidos con el término "escepticismo mediático", lo que significa "un

\footnotetext{
1 Esto demuestra también que el público percibe de manera diferente los distintos tipos de medios de comunicación (televisión, prensa, internet, etc.).
} 
sentimiento subjetivo de desconfianza hacia los medios de noticias establecidos... [por ejemplo]... el sentimiento de que los medios establecidos no son ni creíbles ni confiables, que los periodistas no cumplen con sus estándares profesionales y que los medios de noticias estorban a la sociedad en vez de ayudarla". Los resultados de los sondeos del Pew Research Center durante los últimos 20 años respaldan esta descripción: hace 20 años la mayoría de la gente creía "que las organizaciones de noticias apoyaban a Estados Unidos, que no eran demasiado críticas del país y que ayudaban y no debilitaban a la democracia" (Pew Research Center, 2007: p. 8). La mayoría, en aquellos años, también creía que las coberturas de los medios "informaban bien los hechos" (loc. cit.). Pero desde el final de la década del 80 el escepticismo mediático creció. Hoy en día más de dos tercios de la población estadounidense piensa que los medios son influenciados por personas y organizaciones poderosas y que las coberturas de noticias son tendenciosas. La mayoría piensa que las noticias son imprecisas y un tercio critica el énfasis puesto en las noticias negativas (loc. cit.). Como consecuencia, las personas con altas calificaciones de escepticismo mediático reducen su uso de los medios tradicionales de noticias y optan por fuentes alternativas (Tsfati \& Cappella, 2005).

Los hallazgos de Patterson (2000) sugieren que una de las razones del declive en el uso de los medios tradicionales de noticias podría ser el aumento en la cantidad de noticias blandas. En su sondeo, la mayoría de los encuestados declaró que los contenidos mediáticos habían empeorado en los últimos cinco años. Esta sensación la expresaron especialmente aquellos que utilizaban regularmente los medios de noticias y que habían notado cambios que desembocaron en más noticias blandas. Dos tercios de los encuestados dijeron preferir las noticias duras (presentadas como "noticias que se atienen a las crónicas de grandes eventos o temas que afectan a la comunidad y al país") a las blandas (ofrecidas como "noticias que se enfocan en incidentes específicos, como los crímenes, los incendios o los accidentes"). De la misma manera, cuando a los encuestados se les dio a elegir entre varios títulos eligieron con más frecuencia los que señalaban noticias duras (p. 6). Al mismo tiempo, los datos sobre el uso de los medios demuestran, por ejemplo, que en la televisión se consumen con mayor frecuencia los programas de entretenimiento que los informativos (por ejemplo, en Riddler \& Engel, 2005). 


\subsection{La reputación de los periodistas: confianza, estima y credibilidad}

Una manera de medir el (relativo) prestigio del periodismo es pedirle al público que califique distintas profesiones según su reputación. Una encuesta alemana les pide regularmente a los encuestados que elijan las cinco profesiones que más valoran entre una lista de 22 . En estos sondeos, la reputación relativa de los periodistas, en comparación con otros profesionales como los abogados, los médicos o los profesores universitarios, siempre fue baja. En la última encuesta, realizada en 2005, los periodistas aparecieron en posición decimooctava (Allensbach Archiv, 2005). El porcentaje de encuestados que eligió al periodismo entre las cinco profesiones más valiosas cayó desde un 17 por ciento en 1993 hasta un diez por ciento en 2005 (loc. cit.). En otra encuesta del Allensbach Archiv, casi un tercio (el 29 por ciento) de los alemanes juzgó que los periodistas son particularmente deshonestos, mientras que solamente un 5 por ciento opinó que son particularmente honestos (Noelle-Neumann \& Köcher, 2002: p. 206). Sin embargo, los estudios indican que se percibe a los periodistas como proveedores creíbles de información que ayudan a formar una visión de la sociedad (Ridder \& Engel, 2005). Según una encuesta en Austria, los periodistas son percibidos, por un lado, como muy trabajadores y ambiciosos y, por otro lado, como sobornables y escasamente interesados en producir coberturas objetivas y veraces de las noticias.

Desde 2003, GfK Custom Research evalúa anualmente la confianza que inspiran distintas profesiones en 17 países europeos y en los Estados Unidos. Alrededor de dos tercios de los europeos occidentales y casi la mitad de los estadounidenses dudan de la confiabilidad de los periodistas. Solo el 31 por ciento de la población alemana confía al menos un poco en la profesión. Entre las otras profesiones incluidas en el sondeo, solamente se considera a los gerentes y a los políticos como menos confiables que los periodistas por la población alemana. La confianza en los periodistas es incluso menor entre las poblaciones de Francia (28 por ciento), Gran Bretaña (25 por ciento) y los Países Bajos (24 por ciento) (GfK Custom Research, 2007).

El Edelmann Trust Barometer evalúa, entre otras cosas, la confianza que los líderes de opinión tienen en los medios en 18 países (la pregunta puntual fue: "¿hasta qué punto confías en que los medios hagan lo correcto?"). Se considera a los líderes de opinión como las personas que poseen el 25 por ciento de los mayores ingresos en el país y con fuertes intereses en los medios, la economía y la política. La confianza en los medios es más baja en Alemania y Gran Bretaña, donde 
el 38 por ciento de los grupos de opinión (entre los 35 y los 64 años) confía en los medios. Los mayores índices de confianza en los medios se registraron en India (65 por ciento), Brasil (64 por ciento) y Corea del Sur (60 por ciento) (Edelmann Trust Barometer, 2008: p. 9).

Se podría argumentar que la declinante reputación de los periodistas es parte de una tendencia de desilusión con la política y con las instituciones públicas en general. De todos modos, Cronke y Cook (2007) demostraron, al menos en Estados Unidos, que la pérdida de confianza en los medios y en el periodismo es más veloz que en el caso de otras instituciones. Así sucedió en los años 90, cuando aconteció un cambio radical en la actitud hacia los medios. Notablemente fue antes que nada la típica audiencia consumidora de noticias (las personas de edad, las más educadas y las de mayores ingresos) la responsable de esta tendencia. "Tenemos evidencias claras de que una familiaridad con las noticias genera una falta de confianza en (cuando no un desprecio hacia) la prensa como institución" (Cronke \& Cook, 2007: p. 270).

\subsection{Preguntas de investigación}

En base a los desarrollos descritos anteriormente, el objetivo de este estudio es analizar cómo la población alemana percibe a los periodistas y a los medios de noticias. El foco se puso particularmente en las expectativas de la gente, en su decepción con el trabajo de los periodistas y en su confianza y estima en los periodistas y sus estándares éticos. También se intenta encontrar causas e influencias detrás de la imagen pública de los periodistas.

La investigación se estructuró según las siguientes preguntas de investigación (PI):

PI 1: ¿Cuánta confianza y estima tiene la población alemana en el periodismo y cuáles son los factores decisivos?

PI 2: ¿Cuáles son las expectativas del público sobre el rol de los periodistas, cómo evalúan los primeros el verdadero desempeño de los segundos y cómo se relacionan entre sí las expectativas y los desempeños?

PI 3: ¿Cómo evalúa el público las decisiones que toman los periodistas frente a típicos dilemas éticos (expectativas vs. evaluaciones de desempeño)?

Por los escasos datos empíricos en este campo de estudio, el análisis es en gran medida exploratorio. Por lo tanto, no se sostendrán hipótesis concretas. 


\section{Método}

Para concretar la investigación, se realizó una encuesta telefónica con asistencia computarizada de la población alemana entre noviembre 2007 y enero 2008 . La muestra nacional representativa consistió en 1,054 ciudadanos alemanes de más de 18 años. Los encuestados fueron elegidos a partir de una muestra aleatoria en dos estratos. Primero, se eligieron aleatoriamente los números telefónicos según el llamado diseño Gäbler Häder, un método de marcación aleatoria de números delineado para el sistema alemán de números telefónicos. Se incluyeron todos los números telefónicos de línea en Alemania, independientemente de si estaban o no listados en algún directorio. En un segundo paso, se eligieron aleatoriamente a los encuestados entre los habitantes de cada vivienda a través del método del último cumpleaños. Aunque el trabajo de campo lo realizaron estudiantes de una institución de educación terciaria y aunque se les aseguró a los encuestados de la naturaleza puramente académica de la investigación, el índice de respuesta fue solo del 14 por ciento. Este índice revela los inconvenientes que atraviesan actualmente tanto las encuestas como las investigaciones empíricas en las ciencias sociales en general (Curtin et al., 2005).

Los datos se ponderaron en función del sexo, el tamaño de la vivienda, la edad y el nivel educativo a partir del censo oficial de Alemania (Micro Census, 2005). Por lo tanto, los resultados se consideraron como representativos de la población alemana. Por razones metodológicas (específicamente: para evitar efectos contextuales) y por la duración de las entrevistas, se dividió aleatoriamente la muestra en dos mitades ( $\mathrm{A}$ y B) de 527 encuestados cada una (diseño de boleta dividida) y se les hicieron algunas de las preguntas a solamente una de estas mitades. El margen de error de la muestra completa varió entre los 0,88 y los 3,16 puntos porcentuales, mientras que los márgenes para las muestras divididas variaron entre los 1,94 y los 4,48 puntos porcentuales.

El cuestionario se desarrolló a partir de supuestos teóricos y de encuestas anteriores realizadas en Alemania y Estados Unidos, y luego fue refinado por un grupo focal. De esta manera, surgieron las construcciones teoréticas centrales:

Confianza y estima en los periodistas: se le preguntó a la mitad A de los encuestados si confiaba o no en diez profesiones distintas, entre ellas, los periodistas. El objetivo fue evaluar el porcentaje de la población que confía en ellos y además comparar la confianza depositada en los periodistas con la puesta en otras profesiones, como los médicos, los políticos, los maestros y los abogados. La mitad B 
de los encuestados recibió una pregunta similar pero sobre la "estima" en vez de la confianza.

Expectativas y evaluaciones del rol de los periodistas: los encuestados recibieron una lista de diez objetivos y valores que podrían desear para su vidas y su trabajo profesional, como ser independiente, tolerar opiniones diferentes o ser políticamente activo. Se le consultó a cada encuestado sobre la importancia de cada objetivo y valor en su vida personal. Luego, se le consultó a la mitad A sobre la importancia que estos objetivos y valores deberían tener para los periodistas en el ejercicio de su trabajo, mientras que se le consultó a la mitad B sobre la importancia que estos objetivos y valores realmente tienen para los periodistas.

También se incluyeron preguntas sobre la calidad de las noticias (si empeoraron o mejoraron en los últimos años) y sobre la exposición de los encuestados a las noticias, es decir, cuánta atención les prestan a las noticias y cuánto se informan sobre los últimos hechos ("el deber de mantenerse informado").

Además, se les consultó a los encuestados sobre las nueve características que pueden tener los contenidos noticiosos, como por ejemplo "presentar información contextual" o "presentar opiniones opuestas sobre determinados temas". La mitad A respondió a una pregunta sobre la importancia de estas nueve características para una noticia, mientras que la mitad B respondió a otra pregunta sobre si las nueve características realmente se ajustan a los actuales contenidos noticiosos.

La evaluación de los dilemas periodísticos: a partir de trabajos previos de Köcher (1985) y Schriefers (1992) se describieron diez situaciones típicas en las que un periodista se podría encontrar con un supuesto dilema, al tener que decidir entre distintos valores profesionales, como por ejemplo, entre realizar una cobertura objetiva o poner énfasis en sus ideas personales; entre realizar una cobertura independiente o priorizar los intereses económicos de su medio informativo; y entre su deber de informar y su respeto por los derechos de privacidad. Se les pidió a los encuestados que eligieran en cada caso la decisión periodística correcta (expectativa) y la que probablemente hubiera tomado la mayoría de los periodistas (evaluación). Cada versión del cuestionario incluyó cinco ejemplos. Nuevamente, el interés se orientaba a analizar si existía una discrepancia entre las expectativas del público y su evaluación de la labor periodística.

Cada uno de los dos cuestionarios estandarizados utilizados en esta encuesta incluyó 35 preguntas. Para la mayoría de ellas se emplearon escalas de tipo Likert de 4 puntos. En algunos casos se usaron escalas dicotómicas en las que los encues- 
tados tuvieron que aprobar o desaprobar una declaración. Las declaraciones se formularon tanto positiva como negativamente para prevenir respuestas automáticamente escépticas hacia el periodismo.

\section{Hallazgos}

El análisis se concentró en algunas de las dimensiones de la relación entre el público y el periodismo. Más detalles de los resultados se publicaron en un libro ${ }^{2}$. En este artículo, se presentan los resultados sobre la reputación pública de los periodistas, las expectativas de la audiencia acerca del rol social de los periodistas, las percepciones en torno de la calidad de las noticias y los juicios sobre el comportamiento ético de los periodistas.

\subsection{La ambivalente reputación pública de los periodistas}

Confianza en los periodistas: se evaluó la confianza en los periodistas y en otros nueve grupos laborales al preguntarles a los encuestados si preferirían confiar o desconfiar en cada profesión. Los grupos laborales mencionados tienen similitudes con el periodismo en varios frentes: son profesiones en el sentido sociológico de la palabra (abogados y médicos); son trabajos con algún aspecto didáctico (curas, maestros y profesores); son profesiones en el campo de la comunicación (voceros de prensa y especialistas en publicidad) y también son ocupaciones que tratan con la opinión pública y están sujetas a la cobertura mediática (políticos e investigadores de opinión pública).

Solamente un tercio (el 35 por ciento) de los encuestados confía en los periodistas y entre las diez profesiones, los periodistas ocupan el séptimo puesto en una calificación de confiabilidad (fig. 1). Hasta los investigadores de opinión pública, quienes - gracias a sus fallidos pronósticos durante las elecciones gubernamentales- recibieron muchas críticas en los últimos años, fueron considerados más confiables que los periodistas: la mitad de los encuestados confía en ellos (un 50 por ciento). De manera predecible, la posición más alta la obtuvieron los médicos (79 por ciento) y la última, los políticos (solo el 8 por ciento).

La confianza depositada en cada profesión varía según la edad. Se conformaron los siguientes grupos de edad: de 18 a 24 años, de 25 a 44 años, de 45 a 60 años

\footnotetext{
2 Donsbach, W., Rentsch, M., Schielicke, A.-M. \& Degen, S. (2009). Entzauberung eines Berufs: was die Deutschen vom Journalismus erwarten und wie sie enttäuscht werden. [Desmitificación de una profesión: lo que los alemanes esperan de los periodistas y cómo se decepcionaron]. Konstanz: UVK.
} 
y de más de 60 años. La franja etaria más joven se extiende por 6 años en vez de serlo por 15, como en los otros grupos. De todos modos, el interés mayor estaba orientado a los resultados de los más jóvenes, lo que llevó a establecer franjas de distinta extensión. Los jóvenes aseguraron confiar más que el resto en seis de las 10 profesiones involucradas. Así sucedió con los maestros (el 84 por ciento de los más jóvenes confía en ellos, comparado con el 69 por ciento de los encuestados entre los 25 y 44 años), los voceros de prensa (el 33 por ciento de los más jóvenes confía en ellos, contra el 17 por ciento de la siguiente franja etaria) y los políticos (el 22 por ciento contra el 8 por ciento).

\section{Figura 1. Estima y confianza en las profesiones.}

"A continuación nombro algunas profesiones. Por favor, responda si prefiere o no creer/estimar cada una" (Mejor estimar y mejor creer, en porcentajes).

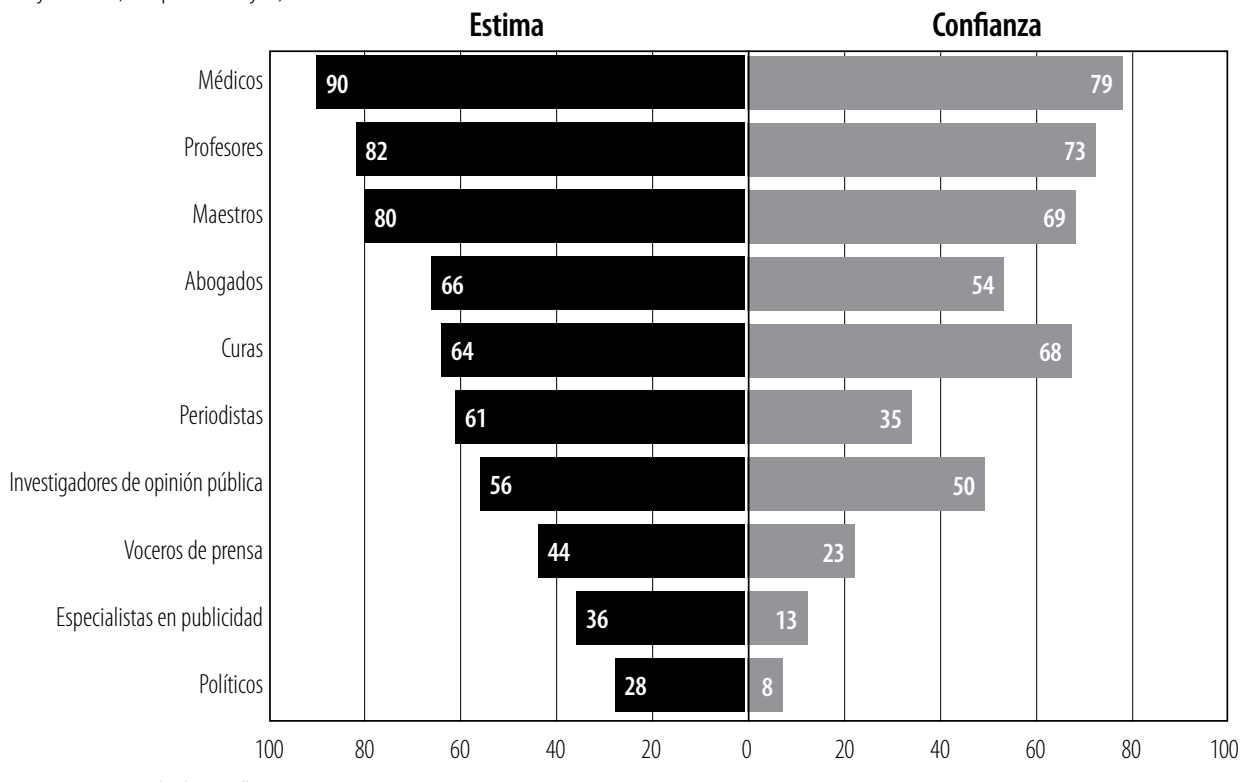

$n=527$ (cada mitad)

Este último resultado, desde una perspectiva democrática, inspira optimismo para el futuro: las nuevas generaciones parecen confiar más en los políticos que el grupo etario medio. Los resultados para la profesión de los periodistas, sin embargo, son diferentes. En este caso, los encuestados entre los 25 y 44 años son los que más confían en ellos (el 50 por ciento), lo que significa que comportan la única franja etaria que confía más de lo que desconfía en los periodistas (fig. 2). Tanto el 
grupo de edad más joven (de los 18 a los 24 años) como el más adulto (de 60 años en adelante) registraron los menores índices de confianza en los periodistas (24 y 23 por ciento, respectivamente). Esta relación extrañamente curvilínea parece ser característica de las calificaciones del periodismo; solo los porcentajes para los voceros de prensa son parecidos.

\section{Figura 2. Confianza en los periodistas por franja etaria.}

"Por favor, diga si prefiere o no confiar en un periodista" (Mejor confiar y mejor no confiar, en porcentajes).

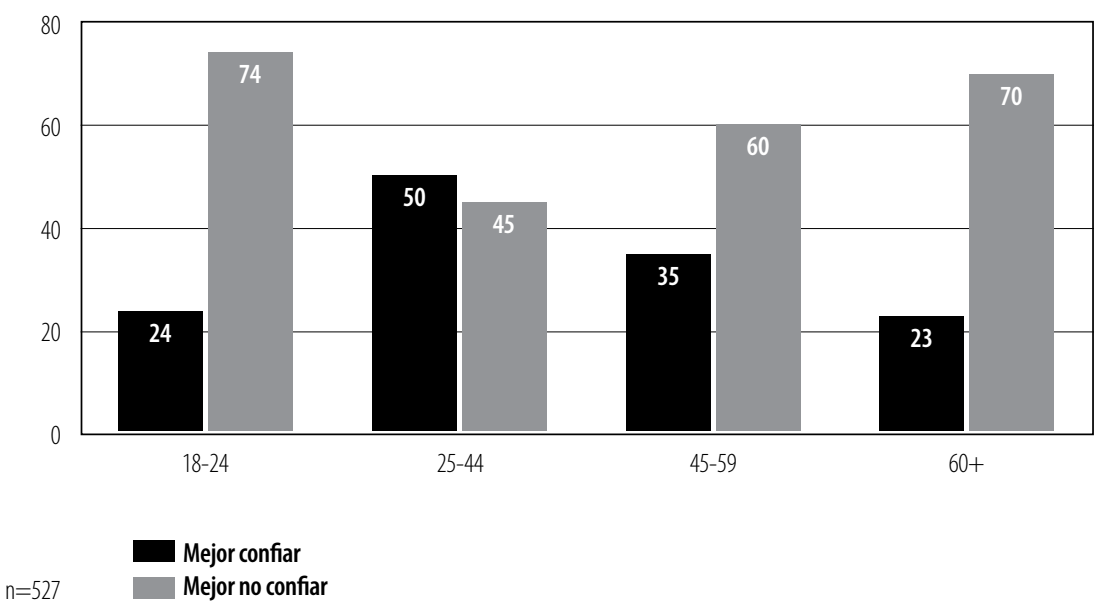

La relación entre el nivel educativo y la confianza depositada en los periodistas es lineal. Cuanto más alto es el nivel de educación formal, más alto también es el porcentaje de los encuestados que confía en los periodistas. Un tercio (el 29 por ciento) de los encuestados con un nivel de educación básico de 8 o 9 años (el "Hauptschule" alemán) confía en los periodistas. Mientras tanto, entre los encuestados que se graduaron de la escuela luego de 10 años (el "Realschule" alemán), el porcentaje es de 36, y entre los que se graduaron de la escuela luego de 12 o 13 años (el "Gymnasium" alemán), el porcentaje es de 46. Se han supuesto dos razones posibles para esta relación: el uso de los medios informativos y la creencia en la democracia. Las personas que leen los periódicos de calidad, algo más común entre los mejor educados, no pierden su confianza en los periodistas y en su desempeño porque regularmente se exponen a productos de alta calidad. Además, las personas mejor educadas pueden haber aprendido sobre el rol de los medios en una sociedad libre en la escuela o en la universidad. En este caso, la confianza en 
los periodistas es un pensamiento idealista que se fundamenta sobre ciertas concepciones de una sociedad democrática.

Estima por los periodistas: la estima difiere de la confianza. Las personas pueden tener una alta estima de ciertas profesiones sin confiar demasiado en ellas, como sucede con ciertas profesiones que demandan habilidades muy especializadas o riesgosas. La gente estima más a los periodistas que lo que confía en ellos. El 61 por ciento de los encuestados dijo estimar a los periodistas, mientras que un tercio aseguró lo contrario. Solamente el 7 por ciento no indicó una opinión definida. De todos modos, aunque los periodistas sean estimados por el doble de los encuestados que confían en ellos, siguen ocupando casi la misma posición en relación con las otras ocupaciones y profesiones: obtuvieron el sexto puesto entre las 10 profesiones involucradas, casi el mismo que en la calificación por confianza, aunque intercambiando lugares con los encuestadores (ver fig. 1).

Todas las ocupaciones en la lista, salvo los curas, son más estimadas que confiadas, y son los periodistas los que muestran la mayor discrepancia. Es posible que la estima mida la imagen y el prestigio de una profesión en una dimensión más normativa, como las expectativas del rol social de una profesión o su especialización, mientras que la confianza mida el verdadero desempeño (percibido). En este sentido, la discrepancia entre estima y confianza podría señalar una brecha entre las expectativas del público y su percepción de los periodistas. Además, las calificaciones de los voceros de prensa y de los especialistas en publicidad son mucho más bajas con referencia a la confianza que a la estima, aunque la diferencia no es tan grande para los periodistas. Por este motivo, se podría tratar de una característica propia de las profesiones comunicacionales en general.

Aunque el nivel de confianza se vio afectado por la edad del encuestado, no se registraron tales discrepancias con los niveles de estima. Los porcentajes de las distintas franjas etarias oscilaron entre el 58 y el 65 por ciento. La influencia de una educación formal en el nivel de estima resultó ser positivo aunque débil, similar a lo registrado en lo relativo a la confianza. El grupo con menos educación formal (Hauptschule) exhibió el porcentaje más bajo de estima en los periodistas (59 por ciento), mientras que el grupo con mayor educación formal (Gymnasium) exhibió el porcentaje más alto (72 por ciento). 


\subsection{Las expectativas del público y su evaluación del rol de los periodistas}

Para medir las expectativas del público respecto del rol de los periodistas, los encuestados indicaron la importancia que le conceden a 10 objetivos y valores que alguien podría desear para su vida y su trabajo profesional. El nivel de importancia se midió a través de una escala tipo Likert de 4 puntos, los cuales oscilaron entre "muy importante", "bastante importante", "no demasiado importante" y "para nada importante". Luego, se le consultó a la mitad A de la muestra sobre la importancia que los periodistas deberían concederles a estos objetivos y valores en su propio trabajo (las expectativas), mientras que a la mitad B de la muestra se le preguntó sobre la importancia que los periodistas realmente les conceden a estos objetivos y valores en su trabajo (la evaluación).

Los resultados de las expectativas demostraron lo que el público probablemente espera de cualquier persona o profesión. Para el análisis, se unieron los puntos "muy importante" y "bastante importante". Casi todos los encuestados dijeron que los periodistas deberían ser "trabajadores y ambiciosos" (96 por ciento), "vivir y actuar autosuficientemente" (94 por ciento), "ayudar a los menos afortunados" (92 por ciento), "tolerar otras opiniones" (92 por ciento), "respetar a los demás" (92 por ciento) y "ser independientes de los demás" (86 por ciento). Por otro lado, un porcentaje considerablemente menor de los encuestados consideró que los ítems relacionados con las necesidades individuales o con la influencia personal de los periodistas deberían ser muy o bastante importantes, como fue el caso de "perseguir metas personales" ( 60 por ciento), "ser políticamente activos" (59 por ciento) $y$ "tener poder e influencia" (36 por ciento).

Sin embargo, si se consideran en soledad, estas expectativas no dicen demasiado sobre la percepción pública de los periodistas y los medios. Por lo tanto, se compararon las expectativas de los encuestados con su percepción de la importancia que los periodistas realmente les conceden a los objetivos y valores mencionados anteriormente. Para este fin, se calculó la diferencia entre el porcentaje de encuestados que respondió que los periodistas deberían considerar muy o bastante importante determinado valor u objetivo y el porcentaje que percibió que los periodistas realmente consideran muy o bastante importante dicho valor u objetivo. Un balance positivo demuestra que el público percibe que los periodistas consideran más importante un valor u objetivo de lo que deberían. Un balance negativo significa que el público percibe que los periodistas consideran menos importante un valor u objetivo de lo que deberían. La figura 3 muestra las discrepancias entre 
las expectativas del público y sus evaluaciones del trabajo periodístico. Las barras negras que apuntan hacia el margen izquierdo señalan balances negativos, mientras que las que apuntan al margen derecho señalan balances positivos.

La relación entre las expectativas y las evaluaciones fue más ecuánime para los ítems "vivir y actuar autosuficientemente", "ser trabajadores y ambiciosos", "ser independientes de los demás", "ser políticamente activos" y "hacer lo que hacen los demás" (fig. 3). Estos resultados demuestran que el público parece creer que los periodistas son relativamente independientes, trabajadores y autosuficientes. $\mathrm{Su}$ compromiso político es tan fuerte como el público piensa que debería serlo.

Figura 3. Discrepancia entre las expectativas del público y su evaluación de los objetivos y valores de los periodistas.

"En su opinión, ¿hasta qué punto deberían los periodistas considerar importantes estos objetivos y valores en su trabajo?" (expectativa) / "iHasta qué punto los periodistas realmente consideran importantes estos objetivos y valores en su trabajo?" (evaluación). (Muy y bastante importante, en porcentajes). Las diferencias entre los porcentajes de las expectativas y las evaluaciones se expresan en puntos porcentuales.

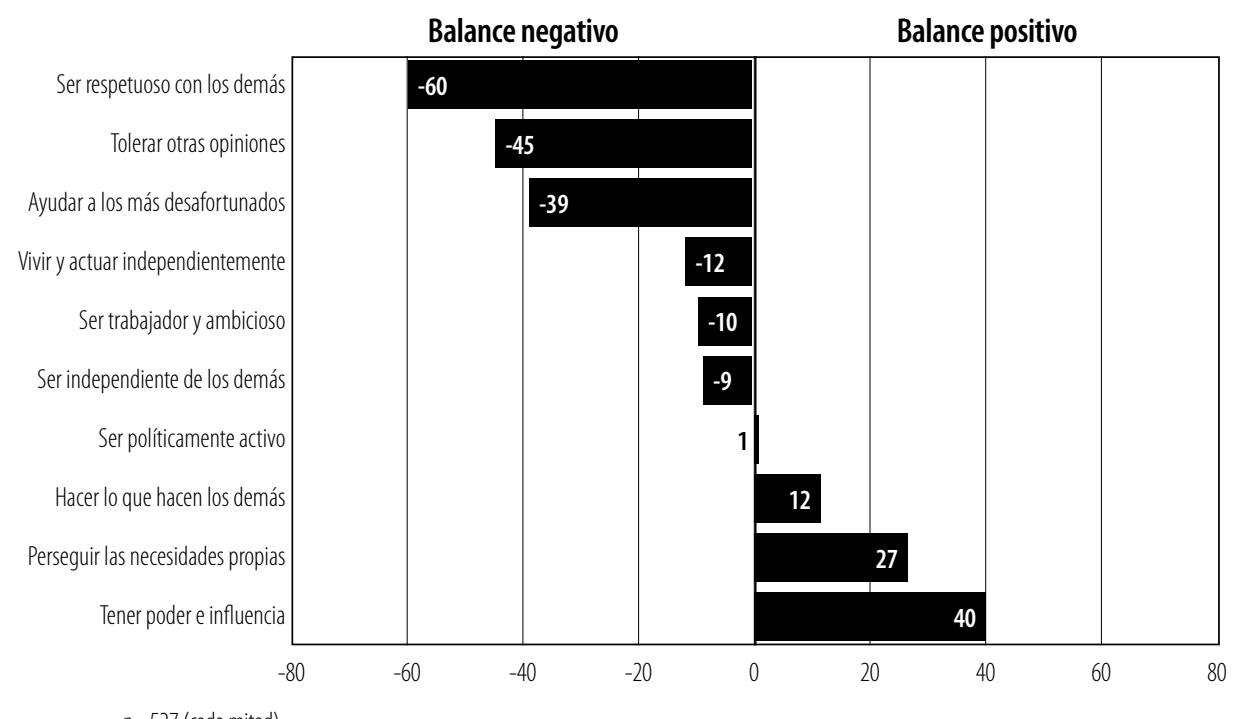

Sin embargo, se registró una inmensa discrepancia entre las expectativas y las evaluaciones del público en los seis ítems restantes (ver fig. 3). Se percibió a los periodistas como más desconsiderados, más intolerantes y más antisociales de lo que el público desearía. Al mismo tiempo, según la percepción del público, los 
periodistas hacen cumplir sus propias necesidades y tienen demasiado poder e influencia. La brecha más amplia entre expectativas y evaluaciones surgió en relación al ítem "ser respetuosos con los demás". Más del 90 por ciento de los encuestados dijeron que los periodistas deberían ser respetuosos con las otras personas, pero ni siquiera un tercio percibió que los periodistas realmente lo fueran. Además, mientras el 92 por ciento de los encuestados pensó que sería importante que los periodistas toleraran las opiniones de los demás, solo el 47 por ciento consideró que los periodistas realmente lo hagan. Esto indica que el público considera que los periodistas no le conceden la importancia que deberían a un estilo de cobertura pluralista. También se podría interpretar que el público entiende que las coberturas actuales son demasiado subjetivas. Además, el 92 por ciento de los encuestados opinó que el rol del periodista como defensor social ("ayudar a los menos afortunados") es importante, mientras que solo el 47 por ciento consideró que los periodistas realmente colaboran de esta manera. Por lo tanto, el público no está muy decidido sobre la neutralidad pura o cuando el rol de los periodistas es militante (Donsbach, 2008).

En total, la comparación entre las expectativas y las evaluaciones de los encuestados en torno de diez objetivos y valores sugiere que el público considera que los periodistas pierden demasiado tiempo persiguiendo sus propias metas, lo que se opone a la idea del periodismo como un servicio social. En otra pregunta, se consultó a los encuestados si actualmente los periodistas son más poderosos que los políticos: el 55 por ciento estuvo de acuerdo, mientras que el 32 por ciento, en desacuerdo. Este primer grupo de encuestados respondió a si pensaba que este estado de cosas era positivo. Solo el 18 por ciento respondió afirmativamente, mientras que el 77 por ciento dijo que no.

También se les preguntó a los encuestados cuán importante consideraban personalmente a los 10 ítems en cuestión, para comparar entre las actitudes del público y las que esperan de los periodistas. En general, los encuestados se atribuyen los mismos valores que los que esperan de los periodistas (tabla 1). Sin embargo, se registraron dos excepciones notables: según los encuestados, los periodistas deberían ser más políticamente activos que el público y al mismo tiempo no deberían exponer sus deseos individuales como sí pueden hacerlo los mismos encuestados en sus propios trabajos. 
Tabla 1. Objetivos y valores: la autopercepción del público, sus expectativas y su evaluación de los periodistas.

\begin{tabular}{|c|c|c|c|}
\hline (Muy o bastante importante, en porcentajes) & Valores del público & $\begin{array}{l}\text { Expectativas públicas } \\
\text { de los periodistas }\end{array}$ & $\begin{array}{l}\text { Percepción pública } \\
\text { de los periodistas }\end{array}$ \\
\hline & $\mathrm{n}=1,054$ & $n=527$ & $n=527$ \\
\hline Vivir y actuar independientemente & 98 & 94 & 82 \\
\hline Ser respetuoso con los demás & 97 & 92 & 32 \\
\hline Tolerar otras opiniones & 96 & 92 & 47 \\
\hline Ser trabajador y ambicioso & 92 & 96 & 86 \\
\hline Ayudar a los más desafortunados & 91 & 92 & 53 \\
\hline Ser independiente de los demás & 89 & 86 & 77 \\
\hline Perseguir las necesidades propias & 80 & 60 & 87 \\
\hline Ser políticamente activo & 40 & 59 & 60 \\
\hline Tener poder e influencia & 28 & 36 & 76 \\
\hline Hacer lo que hacen los demás & 6 & 11 & 23 \\
\hline
\end{tabular}

\subsection{Percepciones de la calidad de las noticias}

Además de la percepción del público acerca de los periodistas, también se analizaron sus expectativas y evaluaciones acerca del contenido de las noticias. Consultados sobre los cambios por los que atravesó dicho contenido, el 19 por ciento lamentó que las noticias hubieran empeorado en los últimos años, mientras que el 36 por ciento aseguró que las noticias habían mejorado y el 41 por ciento opinó que no habían cambiado. También se les preguntó a los encuestados cuánta atención les habían prestado a las noticias en los últimos años. El 40 por ciento declaró que actualmente presta más atención que antes a las noticias, solo el 12 por ciento respondió que presta menos atención y el 47 por ciento no notó ningún cambio. Más de dos tercios (el 70 por ciento) aseguró haber leído noticias sobre los últimos sucesos del día anterior $(\mathrm{n}=1.054)$. Se registró una relación lineal entre el consumo de noticias y la edad. Solamente el 52 por ciento de la franja etaria más joven (de 18 a 24 años) se había informado sobre las noticias del día anterior, en comparación con el 62 por ciento de aquellos entre los 25 y 44 años, el 74 por ciento de aquellos entre los 45 y 59 años y el 82 por ciento de los mayores de 60 años.

Para medir las expectativas y las evaluaciones del público acerca de los contenidos de las noticias, se usaron nueve características que pueden mostrar dichos 
contenidos. Nuevamente, se buscaron discrepancias entre las expectativas y las evaluaciones. Como muestra la figura 4, el público percibió un déficit en el contenido de las noticias en cuanto a la "exposición detallada de los antecedentes". Según los encuestados, el pluralismo en el contenido de las noticias ("presentar opiniones enfrentadas sobre determinados temas") no se practica tanto como se debería. El público percibió que el trabajo periodístico es demasiado subjetivo y demandó que se informen más hechos y opiniones enfrentadas y menos noticias pensadas para estimular sentimientos y emociones. Esto resulta especialmente interesante, ya que dicha estimulación es una de las estrategias para atraer más usuarios a los medios de noticias.

Figura 4. Discrepancia entre las expectativas del público y sus evaluaciones de la calidad de las noticias.

"En su opinión, ¿cuán importantes son las siguientes características para las noticias en la televisión, los diarios e internet?" (expectativas) /“ ¿Hasta qué punto aplican las siguientes características para las noticias en la televisión, los periódicos e internet?" (evaluación). (Muy y bastante importante y realmente aplican, como porcentajes). Las diferencias entre los porcentajes de las expectativas y las evaluaciones se expresan en puntos porcentuales.

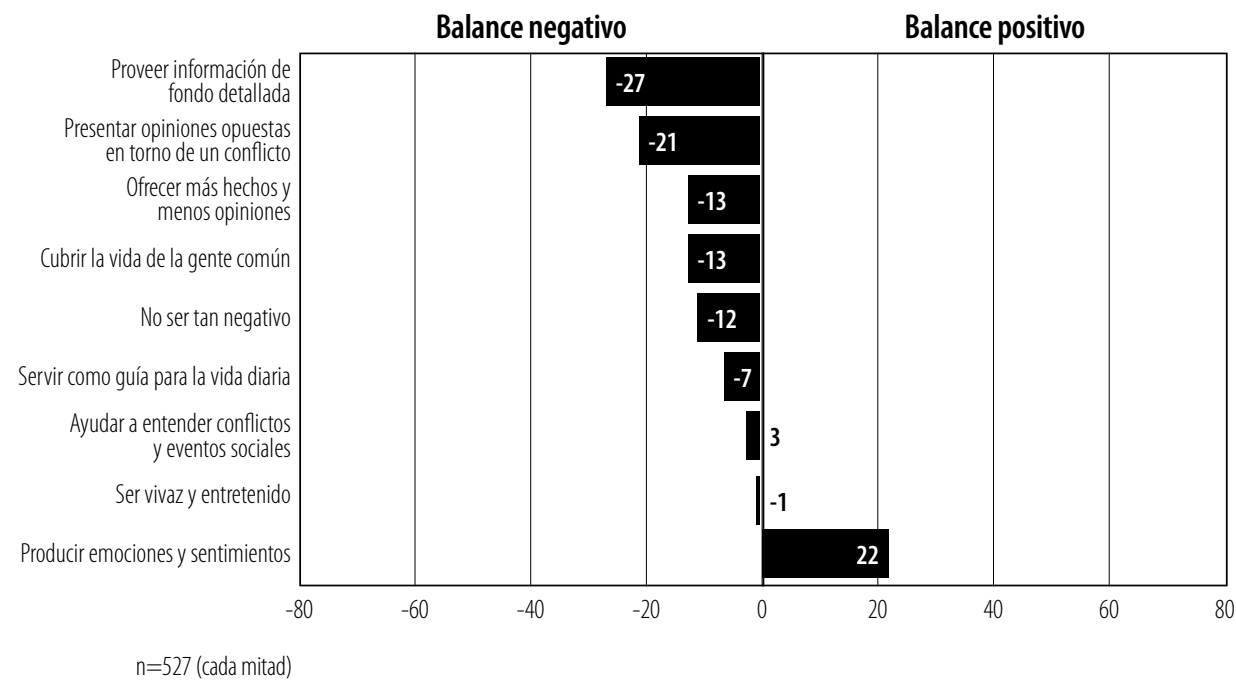

Además, se les preguntó a los encuestados qué piensan sobre las noticias en general $y$, para que formulen sus respuestas, se les proporcionaron siete atributos para describir los contenidos de las noticias. Entre el 30 y el 40 por ciento de los encuestados opinó que las noticias son manipuladas y demasiado prosaicas, sensacionalistas y frívolas. Por lo tanto, una considerable proporción de la audiencia 
condenó la calidad del periodismo al negar que cumpla con las grandes características que debería tener para el ejercicio de su función social.

\subsection{Percepciones de las actitudes de los periodistas en dilemas éticos}

Había también interés sobre la opinión del público acerca de los típicos dilemas que enfrentan los periodistas diariamente. Para este fin, se formularon situaciones con dos alternativas opuestas que un periodista podría elegir. En la mayoría de estos escenarios no había una alternativa que podría considerarse como objetivamente "correcta". Nuevamente, el interés se orientaba a comparar las expectativas y las evaluaciones del público. Las situaciones fueron formuladas a partir de las siguientes dimensiones: objetividad, consideraciones éticas, noticias blandas contra noticias duras, cuestiones de privacidad e independencia económica.

Objetividad. En uno de los ejemplos, un periodista decide no publicar información que contradice su propia opinión. El ejemplo se presentó de esta manera: "Un periodista entrevista a un físico sobre la energía nuclear. En la entrevista, el científico indica que piensa que la energía nuclear es una tecnología positiva para el medio ambiente. Esta posición contradice la opinión del periodista. Por lo tanto, el periodista no publica la entrevista. ¿Es una decisión aceptable o no?”. Solamente el 33 por ciento de la población consideró aceptable no publicar la entrevista, mientras que el 65 por ciento opinó lo contrario. Sin embargo, el 61 por ciento consideró que los periodistas tienden a tomar decisiones de esta forma, mientras que el 35 por ciento opinó que pocas veces o casi nunca ocurren situaciones como el ejemplo.

El segundo caso trajo consigo la pregunta de si los periodistas deberían tomar partido en cuestiones políticas. Se preguntó: "Dos periodistas están cubriendo una convención partidaria. Ambos piensan que las políticas del partido son peligrosas. El periodista A cubre el evento de manera totalmente imparcial. El periodista B remarca los aspectos peligrosos del partido en su artículo. ¿Cuál de los dos cubre el evento como se esperaría de un periodista?". Más de la mitad de los encuestados (el 58 por ciento) pensó que la imparcialidad era el camino correcto, mientras que el 39 por ciento opinó que un periodista debería poner énfasis sobre los aspectos peligrosos del partido político. Nuevamente, la realidad percibida difiere de las expectativas: solo el 31 por ciento pensó que los periodistas alemanes se hubiera comportado imparcialmente en la situación anterior, mientras que el 58 por ciento opinó que el periodista B representa al periodista tipo. Curiosamente, los encues- 
tados de la franja etaria más joven (de 18 a 24 años) y los de la más adulta (más de 60 años) fueron quienes desearon mayor imparcialidad (fig. 5).

\section{Figura 5. Mayor demanda de coberturas objetivas.}

“Dos periodistas están cubriendo una convención partidaria. Ambos piensan que las políticas del partido son peligrosas. El periodista A cubre la convención con total imparcialidad. El periodista B remarca los aspectos peligrosos en su artículo. ¿Cuál de los dos actúa como lo esperaría de un periodista?" (como porcentaje).

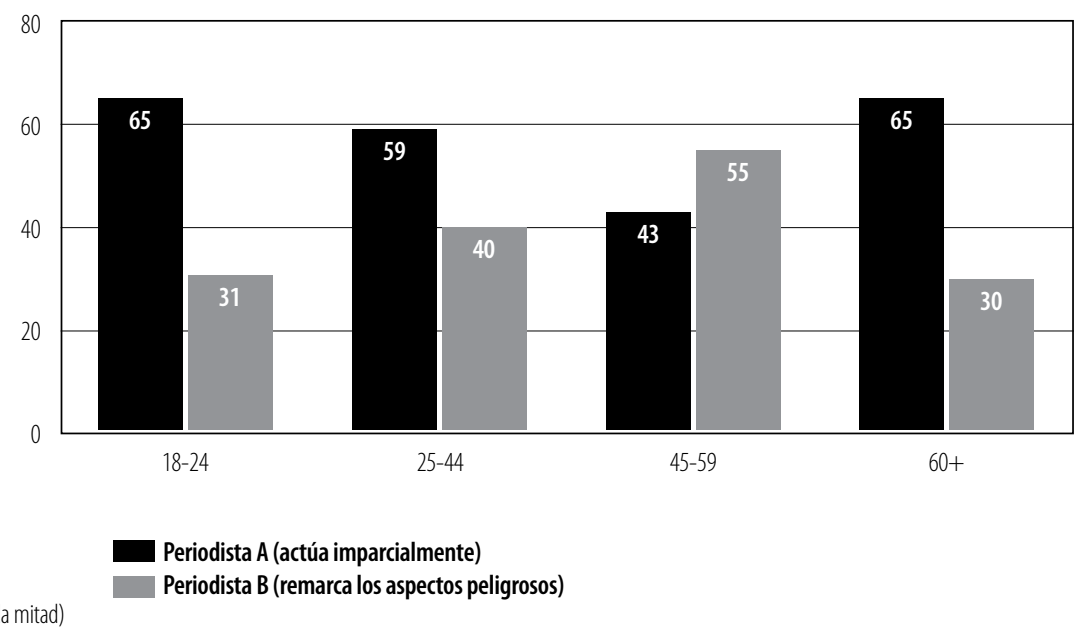

Gran parte de la población parece tener una idea clara de lo que implica una cobertura objetiva, al mismo tiempo que no ve reflejada esta idea en las prácticas periodísticas. En las coberturas de asuntos políticos controvertidos, las opiniones y las evaluaciones personales de los periodistas deberían tener menor prioridad, según el público.

Consideraciones morales. El deber periodístico de informar a menudo entra en conflicto con consideraciones morales. Se les preguntó a los encuestados: "Un diario cubre un ataque terrorista en Afganistán y muestra una foto de un soldado alemán muerto. ¿Es moralmente aceptable esta ilustración?”. El 47 por ciento pensó que publicar la foto sería aceptable, mientras que el 48 por ciento criticó la decisión. Luego, se preguntó si sería o no aceptable publicar una foto de un civil afgano muerto. En este caso, solamente un 26 por ciento consideró aceptable la publicación de la foto, mientras que un 72 por ciento se manifestó en contra. Al tener que evaluar el trabajo periodístico real, el 58 por ciento declaró que la publicación de fotografías con civiles muertos en zonas de guerra es común, mientras que 
el 38 por ciento opinó que sucede pocas veces o nunca. Por lo tanto, respecto de la aceptabilidad moral, el público expresa un juicio diferenciado. Puede ser que la muerte de un soldado sea interpretada como un evento profesional, mientras que la ilustración de civiles muertos interfiera demasiado en la privacidad personal.

Noticias blandas contra noticias duras. Se formularon tres casos en los que se toman decisiones periodísticas entre noticias blandas y duras y entre coberturas personalizadas y factuales: "Dos periodistas están cubriendo una convención partidaria. El periodista A informa sobre el programa del partido. El periodista B se enfoca en el desempeño del líder partidario. ¿Cuál de los dos cubre el evento como se esperaría de un periodista?". El 76 por ciento de los encuestados esperan que los periodistas informen sobre el programa partidario, mientras que el 19 por ciento espera que se enfoquen en las cualidades del líder del partido. En contraste, la mayoría de los encuestados supone que la mayoría de los periodistas se enfocaría en este último (el 58 por ciento) y solo el 31 por ciento considera que los periodistas informarían sobre el programa.

Las expectativas del público con respecto de las noticias blandas y duras se estudió a partir de un segundo ejemplo: "Un periodista está cubriendo una sesión parlamentaria. La cobertura se enfoca en los errores verbales de un político y en las reacciones de sus delegados". Un encuestado de cada cinco (el 21 por ciento) pensó que se trataba de una actitud aceptable, pero el 75 por ciento no estuvo de acuerdo. En contraste, la mayoría de los encuestados opinó que la mayor parte de los periodistas realmente informa de esta manera, es decir, se enfoca en contenidos blandos. Curiosamente, aunque los periodistas a menudo piensan incrementar su audiencia al informar sobre temas blandos o propios de los tabloides, el público parece demandar lo contrario.

Cuestiones de privacidad. El ejemplo fue presentado de la siguiente manera: "Un actor famoso se toma unas vacaciones con su familia. Un periodista se aloja en el mismo hotel y toma fotografías del actor jugando con sus hijos en la pileta". El 19 por ciento de los encuestados consideró aceptable esta situación, mientras que el 79 por ciento opinó lo contrario. Una segunda versión de esta pregunta (acercada a la mitad B de la muestra) excluyó a los hijos. Los resultados fueron parecidos: el 83 por ciento expresó que no es aceptable tomar fotos del actor (por sí solo) en la pileta. Sin embargo, en ambas versiones de la pregunta, la gran mayoría de los encuestados (el 91 por ciento) declaró que los periodistas normalmente toman fotografías de situaciones similares, lo que indica una gran discrepancia entre ex- 
pectativas y evaluaciones en este caso. Ante los ojos del público, la privacidad de las celebridades es un bien que merece ser protegido y que es amenazado por el periodismo sensacionalista. El interés del público en este tipo de notas puede no ser tan alto como piensan los periodistas. Por lo tanto, sería dudoso justificar la violación de derechos personales en nombre de este supuesto interés.

Independencia económica. El interés también estaba orientado a saber cómo el público evalúa las situaciones donde los periodistas tienen que lidiar con presiones económicas. El primer ejemplo se refirió a la influencia de los clientes publicitarios: "Un diario encontró un nuevo cliente de publicidad. Al poco tiempo, el diario publica un artículo positivo sobre esta compañía. ¿Esto es aceptable?”. Casi la mitad de los encuestados no vio ningún problema con esta decisión: el 47 por ciento consideró apropiado publicar el artículo positivo, mientras que el 48 por ciento no estuvo de acuerdo, lo que demuestra que grandes sectores del público no esperan que los periodistas sean completamente ajenos a las presiones económicas. Nuevamente, se registró una pequeña discrepancia entre las expectativas y las evaluaciones: el 65 por ciento de los encuestados opinó que este tipo de situaciones ocurre frecuentemente, mientras que el 28 por ciento consideró que suceden escasas veces o nunca. Desde el punto de vista del público, la dependencia que generan los intereses no periodísticos parece ser parte de la rutina diaria de las oficinas editoriales, lo que no contradice severamente los estándares del periodismo. Otra interpretación posible es que esta práctica está tan presente en la percepción del público, que ya fue aceptada por casi la mitad de la audiencia.

El segundo ejemplo que analizó la evaluación pública de las presiones económicas en el periodismo se presentó de la siguiente manera: "Un periodista quiere informar sobre vehículos todo terreno. Participa en un viaje a Dubai, donde se presentaría el nuevo vehículo. El fabricante paga su viaje". Los resultados son similares a los del primer ejemplo: mientras el 44 por ciento consideró que la situación no es problemática, el 53 por ciento pensó que sí lo es. Curiosamente, la franja etaria más joven (de 18 a 24 años) fue la que se mostró más de acuerdo con esta actitud (un 61 por ciento, fig. 6). En cuanto al comportamiento de los periodistas, el 69 por ciento de los encuestados percibió que los periodistas normalmente actúan de esta manera, mientras que el 35 por ciento consideró que casi nunca se comportan así. La aprobación de esta práctica por los más jóvenes sugiere que la aceptación del patrocinio periodístico es cada vez más amplia y que no es entendido 
necesariamente como algo que contradice la práctica del periodismo independiente y profesional.

Figura 6. Los más jóvenes aceptan el patrocinio del periodismo.

"Un periodista quiere informar sobre vehículos todo terreno. Participa de un viaje a Dubai, donde se presenta al nuevo vehículo. El fabricante paga el viaje del periodista. ¿Esto es aceptable o no?" (como porcentaje).

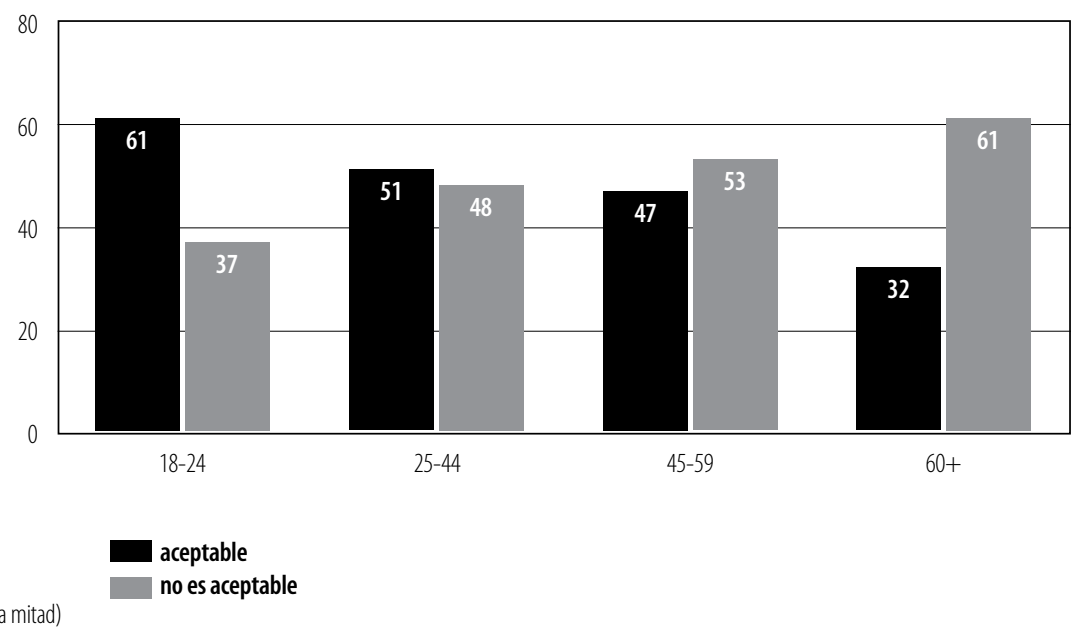

\subsection{La percepción del desempeño periodístico y su influencia en la confianza y la estima}

Finalmente, otro interés se orientaba a qué percepciones del desempeño periodístico podrían afectar la confianza y la estima del público. Por cuestiones de espacio, no se pudo consultar a los encuestados sobre sus expectativas y percepciones acerca de los objetivos y valores profesionales de los periodistas (y, por lo tanto, faltan datos de discrepancias a nivel individual). Por esta razón se restringió el análisis a las percepciones de la calidad del periodismo y de la actitud de los periodistas en momentos decisivos. Se calcularon pruebas de $\chi^{2}$ [chi al cuadrado] para tabulaciones cruzadas con el fin de analizar si las discrepancias entre la confianza y la estima en los distintos grupos encuestados eran significativas.

Existe solo una relación limitada entre la percepción de las distintas cualidades de las noticias y la confianza y la estima que la gente deposita en los periodistas. La confianza no se afecta ni positiva ni significativamente por el hecho de que las noticias no sean percibidas como frívolas, prosaicas o aburridas. En el primer caso, 
el 27 por ciento de quienes percibieron que las noticias son frívolas y el 38 por ciento de quienes no las advirtieron así expresaron confianza en los periodistas $\left(\chi^{2}=7,29 ; p<0,05\right)$. Esto probablemente signifique que las personas con mayores expectativas de calidad periodística se decepcionarán más ante las tendencias actuales hacia el sensacionalismo y el entretenimiento periodístico.

La estima de la gente hacia los periodistas solo fue afectada significativamente por la percepción de las noticias como demasiado sensacionalistas. Pero hasta en este caso las diferencias fueron mínimas $\left(61 / 65\right.$ por ciento; $\left.\chi^{2}=12,40 ; \mathrm{p}<0,05\right)$. Se puede concluir, entonces, que, salvo en conexión con la confianza, la estima es más o menos independiente de las percepciones públicas de calidad periodística.

Además, se analizó hasta qué punto la confianza y la estima son afectadas por la discrepancia entre cómo el público espera que los periodistas se comporten y cómo los primeros perciben que los segundos realmente actúan. Para cada situación se concibieron nuevas variables que midieron si las expectativas de los encuestados correspondieron con sus percepciones. Una variable adicional midió dicha correspondencia en cinco situaciones diferentes (el valor "satisfacción predominante" describió a los encuestados cuyas expectativas correspondieron con sus percepciones en 3 o más situaciones, mientras que el valor "insatisfacción predominante" describió a los encuestados cuyas expectativas y percepciones correspondieron en dos casos o menos).

En todas las situaciones analizadas predominó la (percibida) insatisfacción del público. En un promedio de 1,7 (desviación estándar = 1,12) situaciones (de 5) el público opinó que los periodistas se comportarían como se espera de ellos y en un promedio de 2,9 (desviación estándar $=1,20$ ) situaciones los encuestados opinaron que los periodistas no cumplirían con las expectativas. Esto demuestra nuevamente una notable discrepancia entre las expectativas del público y las actitudes percibidas de los periodistas. Aquellos encuestados cuyas expectativas y percepciones correspondieron entre sí aseguraron estimar mucho más a los periodistas que aquellos que consideraron que los periodistas no cumplen con sus expectativas. Del primer grupo, el 68 por ciento dijo estimar a los periodistas, mientras que en el segundo grupo solo el 57 por ciento $\left(\chi^{2}=10,08\right.$ : $\left.p<0,05\right)$ pensó lo mismo. Los resultados del nivel de confianza revelaron la misma tendencia, pero no fueron estadísticamente significativos $\left(\chi^{2}=4,39 ; \mathrm{p}<0,05\right)$.

Al mirar más de cerca cada situación, se encuentra una diferencia significativa en el nivel de estima en tres de los cinco casos. En el ejemplo de la privacidad 
(el actor en la pileta), el 68 por ciento de los encuestados cuyas expectativas y percepciones correspondieron entre sí estimó a los periodistas, en comparación con el 59 por ciento cuyas expectativas y percepciones fueron distintas $\left(\chi^{2}=8,50\right.$; $\mathrm{p}>0,05)$. En el ejemplo del periodista que debía optar entre informar sobre el programa o sobre el líder partidario, también se registró una discrepancia en la estima entre aquellos con expectativas cumplidas (el 64 por ciento) y aquellos con expectativas incumplidas (el 59 por ciento; $\chi^{2}=6,27 ; p<0,05$ ). En el ejemplo sobre la publicación de un artículo positivo acerca de un nuevo cliente publicitario, la discrepancia fue similar (68 y 57 por ciento) $\left(\chi^{2}=9,34 ; \mathrm{p}<0,01\right)$. En general, se encuentra una relación débil entre la satisfacción percibida de las expectativas del público y la estima que el público tiene de los periodistas.

Las calificaciones de confianza fluctuaron considerablemente según el cumplimiento de las expectativas en solo uno de los cinco ejemplos (el artículo sobre vehículos todo terreno). El 42 por ciento de los encuestados cuyas expectativas y percepciones coincidieron aseguraron confiar en los periodistas, mientras que solamente el 31 por ciento de quienes percibieron que los periodistas no cumplen con sus expectativas expresaron lo mismo $\left(\chi^{2}=6,19 ; p<0,05\right)$. Sin embargo, no se registraron tales discrepancias en los otros cuatro ejemplos. El nivel de confianza parece ser independiente del cumplimiento de las expectativas del público.

\section{Resumen y discusión}

El objetivo de este estudio fue investigar cómo el público considera a los periodistas, cuáles son sus expectativas y cómo perciben que los periodistas cumplen con dichas expectativas. También se buscaron variables que influyan en la estima y la confianza.

La reputación de los periodistas es una espada de doble filo. La estima que el público - alemán, en este caso- tiene de los periodistas es relativamente alta y casi dos tercios de la población estima a la profesión. Sin embargo, aunque la confianza es menor que la estima para casi todas las profesiones, la mayor discrepancia ocurre con los periodistas. Ni siquiera un tercio de los alemanes confía en los periodistas. Aunque el estatus público del periodismo es alto, la gente duda de la confiabilidad de la profesión.

Globalmente, los resultados muestran una gran brecha entre las expectativas del público y su percepción del desempeño real de los periodistas. En este artículo se puso el foco en los objetivos y en los roles de los periodistas, las características 
del contenido de las noticias y las actitudes de los periodistas en situaciones típicas de la profesión. Muchos de los hallazgos sugieren que el público conserva una imagen negativa de los periodistas, al percibirlos como demasiado desconsiderados, intolerantes y poderosos. Los encuestados percibieron que los intereses individuales de los periodistas resaltan demasiado y que escasea la actividad social impulsada por la responsabilidad periodística.

Además, no coincidieron las expectativas de los contenidos de las noticias con las evaluaciones de dichos contenidos, aunque en este caso la brecha fue menor. El público parece demandar noticias más serias y fácticas y menos blandas y de entretenimiento. De todos modos, el contenido blando y de entretenimiento sigue vendiendo mejor, por lo que las respuestas de los encuestados pueden haber tendido hacia lo socialmente aceptable. Los juicios del público acerca de la calidad de las noticias fueron negativos y resulta especialmente interesante la evaluación de las noticias como productos manipulados.

Más variadas fueron las evaluaciones de los encuestados en lo referente a las decisiones de los periodistas frente a dilemas éticos propios de la profesión. Para el público, la objetividad periodística y la consideración profesional parecen importar en la cobertura de la esfera privada de una celebridad. Al mismo tiempo, la dependencia económica no fue percibida como una amenaza para el periodismo. El patrocinio y los intereses de los clientes publicitarios fueron aceptados por una gran proporción de los encuestados.

Finalmente, los autores estaban interesados en la relación entre la satisfacción y la insatisfacción de las expectativas del público, por un lado, y la estima y confianza en los periodistas, por otro. La brecha entre expectativas y percepciones solo sirvió como un indicador significativo de confianza y/o estima en algunas situaciones. La congruencia o incongruencia entre expectativas y percepciones afectó la estima en los periodistas en tres de las cinco situaciones, mientras que la confianza se vio afectada en solamente uno de los casos.

Los resultados ofrecen algunas pistas para explicar por qué muchos sondeos en otros países muestran una reputación declinante para la profesión más decisiva en la salud de una democracia. Los datos se adhirieron a este panorama negativo, particularmente uno de ellos: la franja etaria más joven — junto con la más adulta - fue la que admitió confiar menos en los periodistas. Si este dato anuncia el futuro, entonces uno podría preocuparse por el rol de los periodistas en la democracia. Los resultados se ajustan a las caídas que se han registrado en el consumo 
de las noticias y en el cumplimiento del deber de informarse entre las generaciones más jóvenes.

No es fácil evaluar las razones por las que las personas tienen actitudes más positivas o negativas hacia los periodistas. Las personas son críticas de un periodismo demasiado egoísta o poderoso y critican la tendencia general hacia la tabloidización y el sensacionalismo. Sin embargo, su percepción de ciertas situaciones concretas explica solo de forma limitada los cambios en la confianza y estima que reciben los periodistas. Un análisis más completo de estos datos, además de estudios adicionales, son necesarios para profundizar en las percepciones públicas de los periodistas.

Cada sociedad necesita una estructura comunicacional en la que las percepciones de la realidad, los valores, las demandas y las opiniones puedan ser comunicadas de manera válida y creíble entre las personas, sus diversos grupos y el gobierno. Los distintos actores deben confiar en este flujo comunicacional para que la sociedad funcione. El deber fundamental del periodismo es lograr que esta comunicación social se lleve a cabo. Dicho deber no solo es fundamental porque representa el derecho humano de mantenerse informado, sino también porque solamente una estructura comunicacional libre y válida puede conducir hacia la mejor evaluación posible de la realidad. Todo esto solamente funciona si se confía en aquellos a quienes les fue asignado el deber profesional de organizar la comunicación social, de la misma manera que los pacientes confían en sus médicos. Si esta confianza escasea o se encuentra en declive, las personas carecen de una base para erigir sus juicios subjetivos sobre la realidad.

\section{Referencias}

Allensbach (2005). Allensbacher Berichte. Allensbach.

Bernt, J. P., Fee, F. E., Gifford, J. \& Stempel, G. H. (2000). How well can editors predict the reader interest in news. Newspaper Research Journal 21, 2, 2-10.

Cronke, P. \& Cook, T. E. (2007). Disdaining the media: the American public's changing attitudes toward the news. Political Communication, 24, 259-281.

Curtin, R., Presser, S. \& Singer, E. (2005). Changes in telephone survey nonresponse over the past quarter century. Public Opinion Quarterly, 69, 87-98.

D’Alessio, D. \& Allen, M. (2000). Media bias in presidential elections: a meta-analysis. Journal of Communication, 50, 4, 133-156.

Dautrich, K. \& Necci Dineen, J. (1996). Media bias: what journalists and the public say about it. The Public Perspective, Oct./Nov., 7-14.

Donsbach, W. (1982). Legitimationsprobleme des Journalismus. Freiburg und München: Alber. 
Donsbach, W. (2008). Journalists' role perceptions (v. 6, 2605-10). En su: Donsbach, W. (ed.). The international encyclopedia of communication. Malden: Wiley-Blackwell.

Donsbach, W., Rentsch, M., Schielicke, A.-M. \& Degen, S. (2009). Entzauberung eines Berufs: was die Deutschen vom Journalismus erwarten und wie sie enttäuscht werden. Konstanz: UVK.

Edelmann Trust Barometer (2008). Consultado en 2008 [y revisado en noviembre de 2012] en: http://www.slideshare.net/davefleet/edelman-trust-barometer-2008.

Ehmig, S. (2000). Generationswechsel im deutschen Journalismus: zum Einfluss historischer Ereignisse auf das journalistische Selbstverständnis. Freiburg, München: Alber.

Engesser, E. (2003). Journalismus in Fiktion und Wirklichkeit: ein Vergleich des Journalistenbildes in literarischen Bestsellern mit Befunden der empirischen Kommunikationsforschung. Tesis doctoral. Mainz Universität.

GfK Custom Research (2007). Pressemitteilung. Consultado el 26 de octubre de 2008 [rev. en nov. 2012] en: http://www.gfk.com/imperia/md/content/presse/pd_trust_index_2007_dfin.pdf

Glotz, P. \& Langenbucher, W. R. (1969). Der mißachtete Leser: zur Kritik der deutschen Presse. Köln: Kiepenheuer \& Witsch.

Hagen, L. M. (1992). Die opportunen Zeugen: Konstruktionsmechanismen von Bias in der Zeitungsberichterstattung über die Volkszählungsdiskussion. Publizistik, 37, 1, 444-460.

Haskins, J. B. \& Miller, M. M. (1984). The effects of bad news and good news on a newspaper's image. Journalism Quarterly, 61, 3-13.

Hohlfeld, R. (2005). "Der missachtete Leser revisited": zum Wandel von Publikumsbild und Publikumsorientierung im Journalismus (p. 195-224). En: Behmer, M., Blöhbaum, B. \& Scholl, A. (ed.). Journalismus im Wandel: Analysedimensionen, Konzepte, Fallstudien. Wiesbaden: VS.

Karmasin, M. (1996). Journalismus: Beruf ohne Moral? Wien: Linde.

Kepplinger, H. M. (1979). Angepaßte Außenseiter: was Journalisten denken und wie sie arbeiten. Freiburg: Alber.

Kepplinger, H. M. (1989). Instrumentelle Aktualisierung: Grundlagen einer Theorie publizistischer Konflikte (p. 199-220). En: Kaase, M. \& Schulz, W. (ed.). Massenkommunikation: Theorien, Methoden, Befunde. Opladen: Westdeutscher Verlag.

Köcher, R. (1985). Spürhund und Missionar: eine vergleichende Untersuchung über Berufsethik und Aufgabenverständnis britischer und deutscher Journalisten [discurso]. Munich.

Köcher, R. (1986). Bloodhounds or missionaries: role definitions of German and British journalists. European Journal of Communication, 1, 43-64.

Lang, K., Lang, G. E., Kepplinger, H. M. \& Ehmig, S. (1993). Collective memory and political generations: a survey of German journalists Political Communication, 10, 211-229.

McLeod, S. H. \& Chaffee, S. H. (1972). The construction of social reality (p. 50-99). En: Tedeschi, I. T. (ed.). The social influence processes. Chicago: Aldine Atherton.

Martin, R. K., O’Keefe, G. J. \& Nayman, O. B. (1972). Opinion agreement and accuracy between editors and their readers. Journalism Quarterly, 49, 460-468.

Noelle-Neumann, E. \& Kepplinger, H. M. (1978). Journalistenmeinungen, Medieninhalte und Medienwirkungen (p. 41-67). En: Steindl, G. (ed.). Publizistik aus Profession: Festschrift für Johannes Binkowski. Düsseldorf: Droste.

Noelle-Neumann, E. \& Köcher, R. (2002). Allensbacher Jahrbuch der Demoskopie 1998-2002. München: Saur. 
Patterson, T. E. \& Donsbach, W. (1996). News decisions: journalists as partisan actors. Political Communication, 13, 4, 455-468.

Patterson, T. E. (2000). Doing well and doing good: how soft news and critical journalism are shrinking the news audience and weakening democracy: and what news outlets can do about it. En: Report of the Shorenstein Center for the Press, Politics, and Public Policy. Harvard University.

Pratto, F. \& John, O. P. (1991). Automatic vigilance: the attention-grabbing power of negative social information. Journal of Personality and Social Psychology 61, 380-391.

Pew Research Center for The People \& The Press (2002). News media's improved image proves shortlived. Consultado el 26 de octubre de 2008 [y revisado en noviembre de 2012] en: http://peoplepress.org/report/159/news-medias-improved-image-proves-short-lived.

Ridder, Ch.-M. \& Engel, B. (2005). Massenkommunikation 2005: Images und Funktionen der Massenmedien im Vergleich. Media Perspektiven, 9, 422-449.

Schriefers, A. (1992). Ansichten der Bevölkerung zur Rolle und zur Arbeitsweise von Journalisten [tesis]. Mainz.

Schönbach, K. (1977). Trennung von Nachricht und Meinung: Empirische Untersuchung eines publizistischen Qualitätskriteriums. Freiburg, München: Alber.

Tsfati, Y. \& Cappella, J. N. (2003). Do people watch what they do not trust? Exploring the association between news media skepticism and exposure. Communication Research 30, 5, 504-529.

Tsfati, Y. \& Cappella, J. N. (2005). Why do people watch news they do not trust: need for cognition as a moderator in the association between news media skepticism and exposure. Media Psychology 7, 3, 251-272.

Weaver, D. H., Beam, R. A. \& Brownlee, B. J. (2008). The American journalist in the 21st century: news people at the dawn of a new milennium. Mahwah: Erlbaum.

Weaver, D. H. (ed.) (1998). The global journalist: news people around the world. New Jersey: Hampton Press.

Weaver, D. \& Daniels, L. (1992). Public opinion on investigative reporting in the 1980s. Journalism Quarterly, 69, 146-155.

Weischenberg, S., Malik, M. \& Scholl, A. (2006). Die Souffleure der Mediengesellschaft: Report über die Journalisten in Deutschland. Berlin: VS.

Wiegerling, K. (1998). Medienethik. Stuttgart: Metzler.

Willnat, L. \& Weaver, D. H. (1998). Public opinion on investigative reporting in the 1990s: has anything change since the 1980s? Journalism and Mass Communication Quarterly, 75, 449-463.

\section{Correspondencia}

\section{Wolfgang Donsbach}

Technische Universität Dresden

01062 Dresden, Alemania

Wolfgang.Donsbach@tu-dresden.de 